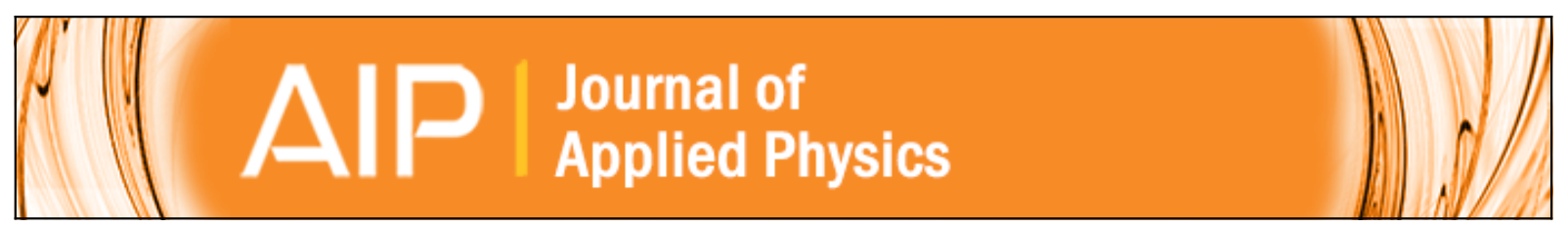

\title{
Optimization of the giant magnetoimpedance effect of Finemet-type microwires through the nanocrystallization
}

A. Talaat, V. Zhukova, M. Ipatov, J. M. Blanco, L. Gonzalez-Legarreta, B. Hernando, J. J. del Val, J. Gonzalez, and A. Zhukov

Citation: Journal of Applied Physics 115, 17 A313 (2014); doi: 10.1063/1.4863484

View online: http://dx.doi.org/10.1063/1.4863484

View Table of Contents: http://scitation.aip.org/content/aip/journal/jap/115/17?ver=pdfcov

Published by the AIP Publishing

\section{Articles you may be interested in}

Giant magnetoimpedance effect and domain wall dynamics in Co-rich amorphous microwires

J. Appl. Phys. 117, 043904 (2015); 10.1063/1.4906503

Structural, magnetic, and magnetostriction behaviors during the nanocrystallization of the amorphous $\mathrm{Ni} 5 \mathrm{Fe}$ 68.5 Si 13.5 B $9 \mathrm{Nb} 3 \mathrm{Cu} 1$ alloy

J. Appl. Phys. 99, 08F104 (2006); 10.1063/1.2162810

Giant magnetoimpedance effect in ultrasoft FeAISiBCuNb nanocomposites for sensor applications

J. Appl. Phys. 98, 014316 (2005); 10.1063/1.1953864

Stress induced magnetic anisotropy and giant magnetoimpedance in Fe-rich glass-coated magnetic microwires

J. Appl. Phys. 94, 1115 (2003); 10.1063/1.1585113

Giant magneto-impedance effect in nanocrystalline glass-covered wires

J. Appl. Phys. 83, 6584 (1998); 10.1063/1.367926

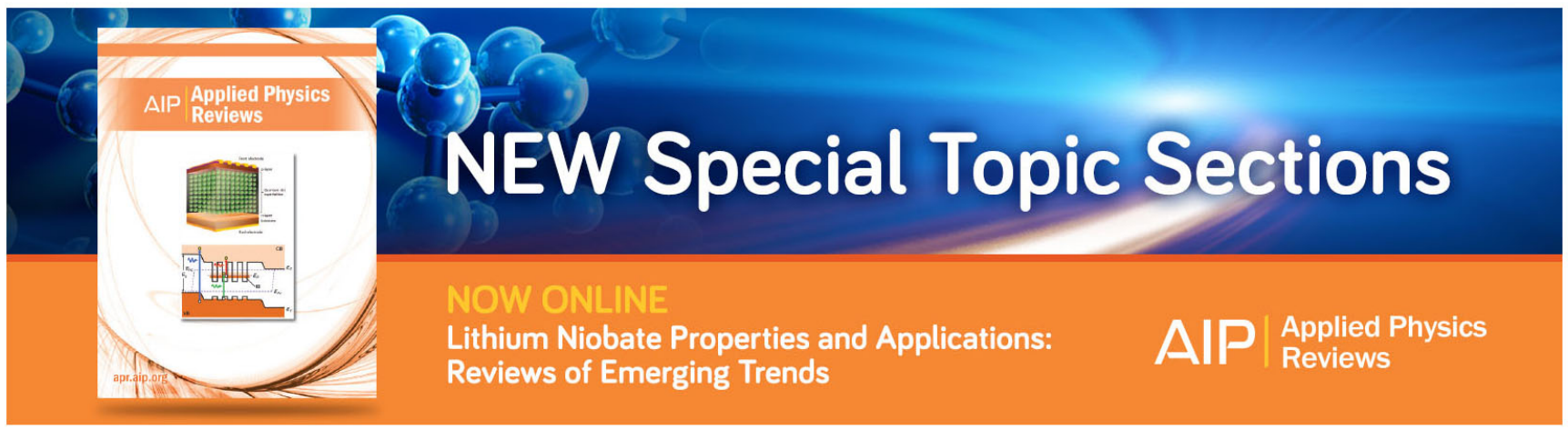




\title{
Optimization of the giant magnetoimpedance effect of Finemet-type microwires through the nanocrystallization
}

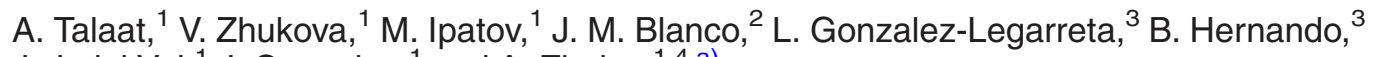 \\ J. J. del Val, ${ }^{1}$ J. Gonzalez, ${ }^{1}$ and A. Zhukov ${ }^{1,4, a)}$ \\ ${ }^{1}$ Dpto. Fisica de Materiales, UPV/EHU, San Sebastian, Spain \\ ${ }^{2}$ Dpto de Fisica Aplicada, EUPDS, 20018 San Sebastian, Spain \\ ${ }^{3}$ Dpto de Física, Universidad de Oviedo, Calvo Sotelo s/n, 33007 Oviedo, Spain \\ ${ }^{4} I K E R B A S Q U E$, Basque Foundation for Science, Bilbao, Spain
}

(Presented 6 November 2013; received 17 September 2013; accepted 30 October 2013; published online 30 January 2014)

\begin{abstract}
We studied correlation of magnetic properties, giant magnetoimpedance (GMI) effect and structure of Finemet-type glass-coated microwires obtained by the Taylor-Ulitovski technique. We observed considerable magnetic softening and increasing of the GMI ratio, $\Delta \mathrm{Z} / \mathrm{Z}$, (from $3 \%$ up to $100 \%$ ) after annealing of studied microwires. On the other hand, even in as-prepared $\mathrm{Fe}_{73.8} \mathrm{Cu}_{1} \mathrm{Nb}_{3.1} \mathrm{Si}_{13} \mathrm{~B}_{9.1}$ microwire, we observed existence of $\alpha$-Fe nanocrystallites with average grain size about $12 \mathrm{~nm}$ and considerable GMI effect $(\Delta \mathrm{Z} / \mathrm{Z}$ up to 50\%). (C 2014 AIP Publishing LLC. [http://dx.doi.org/10.1063/1.4863484]
\end{abstract}

Studies of magnetically soft glass-coated microwires (with metallic nucleus diameters from 1 up to $30 \mu \mathrm{m}$ ) have attracted considerable attention in the last two decades owing to their reduced dimensionality and unusual magnetic properties suitable for technological applications. ${ }^{1,2}$ Most attention has been paid to studies of soft magnetic properties and Giant magnetoimpedance (GMI) effect. ${ }^{3-7}$

Nanocrystalline Fe-based alloys are quite attractive from the point of view of applications, in which more expensive Co-based amorphous alloys are used conventionally. ${ }^{8-15}$ Basically, the main advantage of nanocrystalline Fe-based alloys is higher saturation magnetization. Additionally, nanocrystalline $\mathrm{FeCuNbSiB}$ ribbons annealed at optimum conditions exhibit high GMI effect. ${ }^{11}$

Similar to nanocrystalline ribbons and conventional wires, considerable magnetic softening has been observed in some cases in Finemet-type microwires. ${ }^{11-14}$ But internal stresses induced by glass-coated technique considerably affect the nanocrystallization of the Finemet-type microwires. Consequently, reported GMI ratio values (below 30\%) are rather lower than for Co-rich glass-coated microwires and nanocrystalline ribbons and wires $(100 \%-400 \%){ }^{11,16}$

There are only a few papers reporting GMI effect in nanocrystalline glass-coated microwires. ${ }^{13}$ Consequently, we must consider that the internal stresses typical for Finemettype microwires ${ }^{17-19}$ considerably affect the soft magnetic properties and GMI effect, respectively. Therefore, we suppose that GMI values can be considerably optimized.

We present our last results on studies of the effect of the devitrification on magnetic properties, structure, and GMI of Finemet-type microwires.

We prepared Finemet-type $\mathrm{Fe}_{70.8} \mathrm{Cu}_{1} \mathrm{Nb}_{3.1} \mathrm{Si}_{14.5} \mathrm{~B}_{10.6}$, $\mathrm{Fe}_{71.8} \mathrm{Cu}_{1} \mathrm{Nb}_{3.1} \mathrm{Si}_{15} \mathrm{~B}_{9.1}, \mathrm{Fe}_{73.8} \mathrm{Cu}_{1} \mathrm{Nb}_{3.1} \mathrm{Si}_{13} \mathrm{~B}_{9.1}$, and $\mathrm{Fe}_{70.8} \mathrm{Cu}_{1}$

\footnotetext{
a) Author to whom correspondence should be addressed. Electronic mail: Arkadi.joukov@ehu.es
}

$\mathrm{Nb}_{3.1} \mathrm{Si}_{16} \mathrm{~B}_{9.1}$ glass-coated microwires with different metallic nucleus diameter, $\mathrm{d}$, and total microwire diameter, $\mathrm{D}$, by modified Taylor-Ulitovsky method. ${ }^{1}$ We studied magnetic field dependences of impedance, $\mathrm{Z}$, and GMI ratio, $\Delta \mathrm{Z} / \mathrm{Z}$, and measured hysteresis loops in as-prepared samples and annealed in conventional furnace. For GMI measurements, we used specially designed micro-strip sample holder, described elsewhere. ${ }^{5}$

For structural studies, we used a BRUKER (D8 Advance) X-ray diffractometer with $\mathrm{Cu} \mathrm{K}_{\alpha}(\lambda=1.54 \AA)$ radiation.

Like usually for amorphous microwires, as-prepared and heat-treated at low annealing temperature Finemet-type microwires present considerable dependence of coercivity, $\mathrm{H}_{\mathrm{c}}$, on $\rho$-ratio ( $\left.\rho=\mathrm{d} / \mathrm{D}\right)$ (Fig. 1(a)). Moreover, studied samples exhibit rectangular hysteresis loops in as-prepared state and after annealing at least prior the crystallization (Fig. 1(b)). This shape of the hysteresis loops is related to magnetically bistable behavior typical for Fe-rich amorphous microwires.

As can be appreciated in Fig. 1(b), annealing results in some decreasing of the coercivity.

Annealing performed in conventional furnace for $1 \mathrm{~h}$ results in devitrification of studied samples at annealing temperatures, $\mathrm{T}_{\mathrm{ann}} \geq 550^{\circ} \mathrm{C}$. As deduced from Figure 2(a), a main crystalline peak appears in the range between $42^{\circ}$ and $45^{\circ}$, which correspond to the precipitation of $\alpha-\mathrm{Fe}(\mathrm{Si}) \mathrm{BCC}$ crystallites as well as the other two weak peaks appears in the range between $65^{\circ}$ and $85^{\circ}$ similar to conventional Finemet-type materials. ${ }^{8-10}$ Using the Deybe-Sherrer equation and the width of the crystalline peak we have been able to estimate the average grain size (D) (see Table I).

The GMI effect in most of as-prepared Fe-rich Finemettype microwires is rather small exhibiting $\Delta \mathrm{Z} / \mathrm{Z}$ below $1 \%$ (Fig. 3). The origin of rather sharp changes of $\Delta \mathrm{Z} / \mathrm{Z}$ in the low-field region might be related to fast magnetization switching typical for Fe-rich microwires with rectangular 

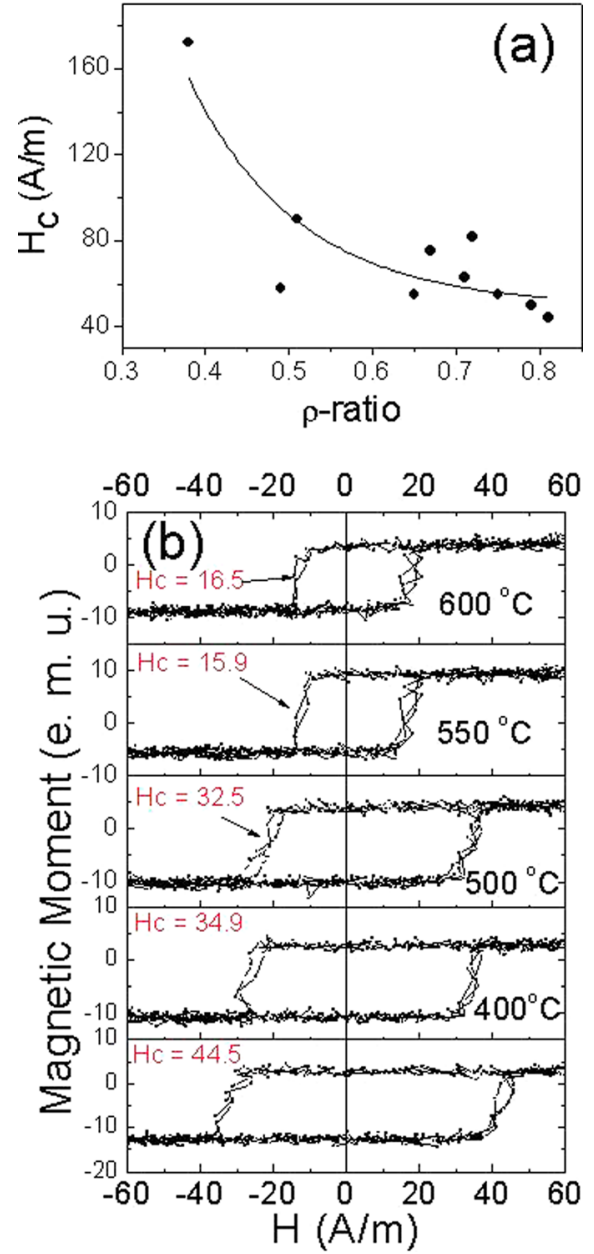

FIG. 1. Dependences of coercivity on $\rho$-ratio for as-prepared $\mathrm{Fe}_{70.8} \mathrm{Cu}_{1}$ $\mathrm{Nb}_{3.1} \mathrm{Si}_{14.5} \mathrm{~B}_{10.6}$ microwires (a) and on annealing temperature for $\mathrm{Fe}_{70.8} \mathrm{Cu}_{1}$ $\mathrm{Nb}_{3.1} \mathrm{Si}_{14.5} \mathrm{~B}_{10.6}$ microwires with $\rho=0.81(\mathrm{~b})$.

hysteresis loops. The exception is the $\mathrm{Fe}_{73.8} \mathrm{Cu}_{1}$ $\mathrm{Nb}_{3.1} \mathrm{Si}_{13} \mathrm{~B}_{9.1}$ microwire with $\rho$-ratio of 0.6 , where we observed quite high $\Delta \mathrm{Z} / \mathrm{Z}$ (up to $\approx 50 \%$, see, Fig. $3(\mathrm{~d}$ )).

We observed that the as-prepared $\mathrm{Fe}_{73.8} \mathrm{Cu}_{1} \mathrm{Nb}_{3.1} \mathrm{Si}_{13} \mathrm{~B}_{9.1}$ microwire with high GMI ratio in fact has nanocrystalline structure, although other as-prepared $\mathrm{Fe}_{70.8} \mathrm{Cu}_{1} \mathrm{Nb}_{3.1} \mathrm{Si}_{14.5} \mathrm{~B}_{10.6}$ microwires with low GMI effect are amorphous (Fig. 2(b)). Consequently, we can assume that nanocrystallization of Fe-rich microwire is the key for achievement of high GMI effect.

In order to achieve such improvement, we studied the effect of annealing on GMI effect of $\mathrm{Fe}_{70.8} \mathrm{Cu}_{1} \mathrm{Nb}_{3.1} \mathrm{Si}_{14.5} \mathrm{~B}_{10.6}$ microwires exhibiting low GMI ratio in as-prepared state. As can be appreciated from Fig. 4 after annealing at $550{ }^{\circ} \mathrm{C}$ for $1 \mathrm{~h}$, we observed drastic increasing of GMI ratio from about $0.5 \%$ to about $100 \%$.

Similar to other Fe-rich amorphous microwires exhibiting rectangular hysteresis loops for as-prepared $\mathrm{FeCuNbSiB}$ microwires, we can consider existence of inner axially magnetized single domain structure surrounded by transversally magnetized outer domain shell. ${ }^{21}$

Nanocrystallization is usually associated with decreasing of the magnetostriction constant and consequently with changes of domain structure as previously reported in ribbons and wires. ${ }^{15,20,22}$
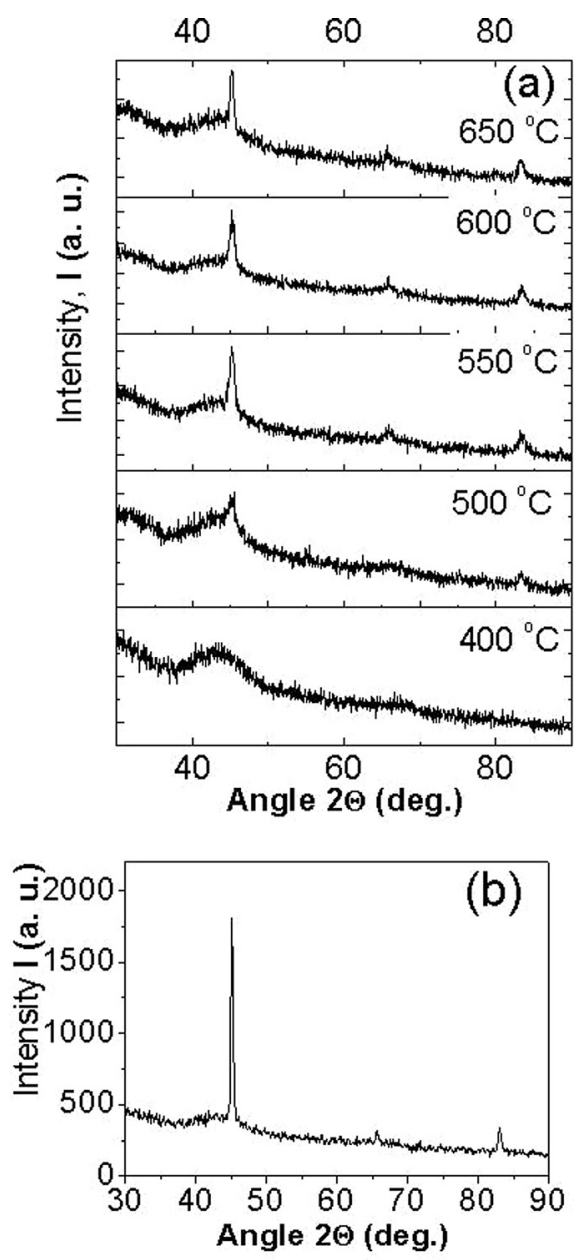

FIG. 2. XRD patterns of microwires $\mathrm{Fe}_{70.8} \mathrm{Cu}_{1} \mathrm{Nb}_{3.1} \mathrm{Si}_{14.5} \mathrm{~B}_{10.6}$ with ratio $\rho \approx 0.65$ after annealing at different temperatures (a) and as-prepared $\mathrm{Fe}_{73.8} \mathrm{Cu}_{1} \mathrm{Nb}_{3.1} \mathrm{Si}_{13} \mathrm{~B}_{9.1}$ (b).

In our studies, these changes of domain structure and magnetostriction constant are indirectly confirmed by drastic increasing of the GMI effect after devitrification induced by the annealing. It is worth mentioning that GMI effect is attributed to the high circumferential permeability usually observed in nearly-zero magnetostrictive wires with bamboo-like outer domain structure. , $^{3,4,21}$

It is worth mentioning that the nanocrystalline structure has been observed in as-prepared microwire with lowest $\rho$-ratio, i.e., with largest relative volume of the glass. One can expect lower quenching rate for this sample because of lower thermal conductivity of insulating glass coating. Indeed in same alloys the nanocrystalline structure has been reported for as-cast samples even in the case of ribbons. ${ }^{23}$

The effect of internal stresses on structure and properties of solids obtained using rapid quenching is related also with

TABLE I. Average grain size (nm) of $\mathrm{Fe}_{70.8} \mathrm{Cu}_{1} \mathrm{Nb}_{3.1} \mathrm{Si}_{14.5} \mathrm{~B}_{10.6}$ microwires with $\rho$ - ratios annealed at different annealing temperature.

\begin{tabular}{lccc}
\hline \hline Sample annealing temperature $\left({ }^{\circ} \mathrm{C}\right)$ & $\rho=0.72$ & $\rho=0.65$ & $\rho=0.81$ \\
\hline 550 & 12 & 17 & 16 \\
600 & 14 & 18 & 15 \\
650 & 27 & 22 & 44 \\
\hline \hline
\end{tabular}



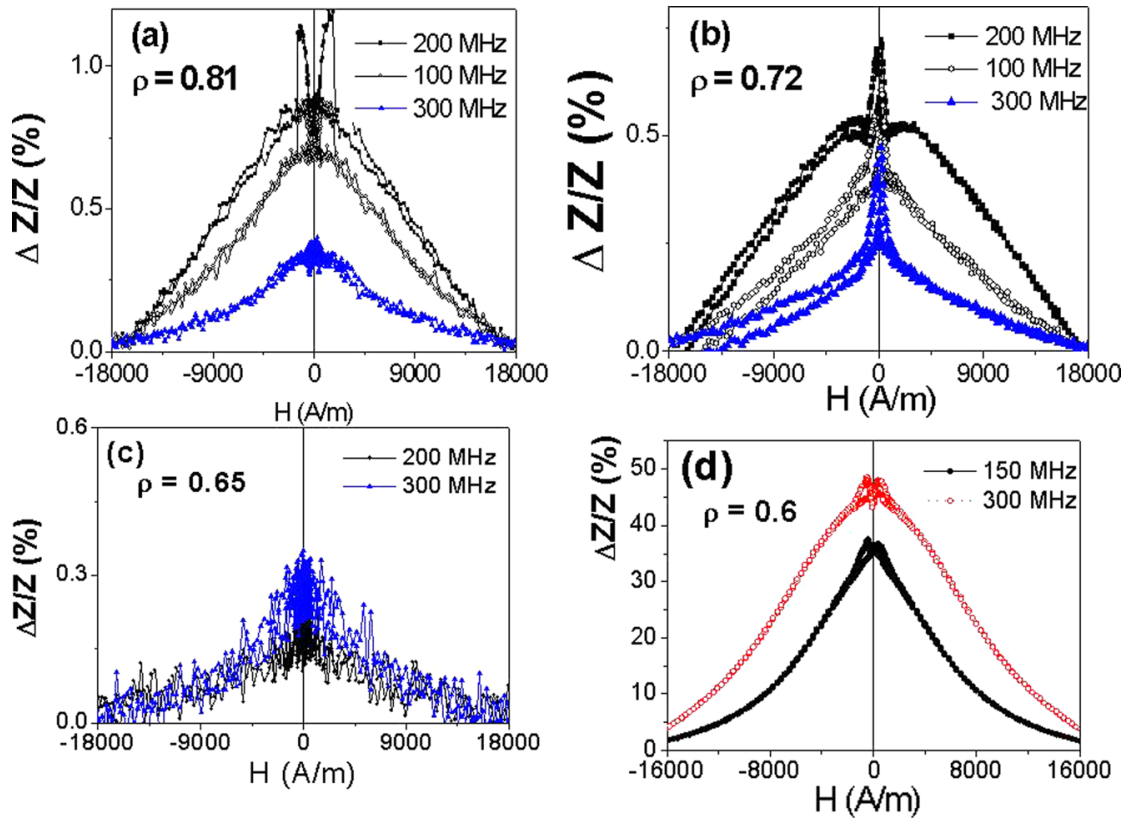

FIG. 3. $\Delta \mathrm{Z} / \mathrm{Z}(\mathrm{H})$ dependences measured in as-prepared $\mathrm{Fe}_{70.8} \mathrm{Cu}_{1} \mathrm{Nb}_{3.1}$ $\mathrm{Si}_{14.5} \mathrm{~B}_{10.6}$ microwires with different geometric ratio $\rho$ (a)-(c) and in $\mathrm{Fe}_{73.8}$ $\mathrm{Cu}_{1} \mathrm{Nb}_{3.1} \mathrm{Si}_{13} \mathrm{~B}_{9.1}$ with nanocrystalline structure (d). the non-equilibrium thermodynamics. In order to understand the structure of the crystalline phases arising during the recrystallization one should take into account that the grains nucleation and growth in the case of glass-coated microwires are related with atomic diffusion under stress. ${ }^{24}$

We can assume that the nanocrystalline structure of $\mathrm{FeCuNbSiB}$ microwires is essential for optimization of the GMI effect.

Concluding in Finemet-type $\mathrm{FeCuNbSiB}$ the reduction of the $\rho$-ratio, results in the rise of coercivity. Magnetoelastic anisotropy affects soft magnetic properties of as-prepared
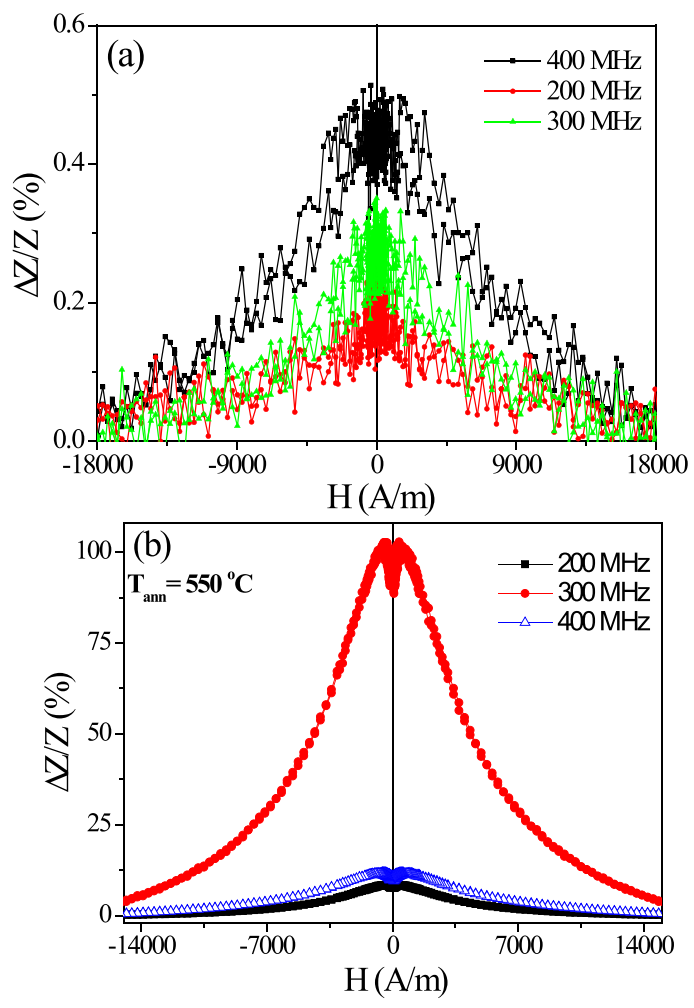

FIG. 4. $\Delta \mathrm{Z} / \mathrm{Z}(\mathrm{H})$ dependences measured in as-prepared (a), and annealed at $550{ }^{\circ} \mathrm{C}$ (b) $\mathrm{Fe}_{70.8} \mathrm{Cu}_{1} \mathrm{Nb}_{3.1} \mathrm{Si}_{14.5} \mathrm{~B}_{10.6}$ microwires with geometric ratio $\rho=0.65$.
FeCuNbSiB microwires. We observed magnetic softening and considerable GMI effect in Finemet-type FeCuNbSiB with nanocrystalline structure even in as-prepared microwires. After adequate annealing of Finemet-type microwires we observed GMI ratio about $100 \%$. The nanocrystallization of $\mathrm{FeCuNbSiB}$ microwires is a key for optimization of the GMI effect.

This work was supported by EU ERA-NET programme under Project "SoMaMicSens" (MANUNET-2010-Basque-3), by EU under FP7 "EM-safety" project and by the Basque Government under Saiotek 11 MICMAGN Project (SPE11UN087). B.H. and L.G.-L. acknowledge the financial support from the Principado de Asturias (SV-PA-13ECOEMP- 47), and L.G.-L. acknowledges a FPI grant of MICINN. Technical and human support provided by SGIker (UPV/EHU, MICINN, GV/EJ, ERDF, and ESF) is gratefully acknowledged.

\footnotetext{
${ }^{1}$ M. Vazquez et al., Phys. Status Solidi A 208, 493 (2011).

${ }^{2}$ D. C. Jiles, Acta Mater. 51, 5907 (2003).

${ }^{3}$ L. V. Panina and K. Mohri, Appl. Phys. Lett. 65, 1189 (1994).

${ }^{4}$ R. Beach and A. Berkowitz, Appl. Phys. Lett. 64, 3652 (1994).

${ }^{5}$ A. Zhukov et al., J. Alloys Compd. 586, S279 (2014).

${ }^{6}$ Y. Honkura, J. Magn. Magn. Mater. 249, 375 (2002).

${ }^{7}$ T. Uchiyama et al., IEEE Trans. Magn. 47(10), 3070 (2011).

${ }^{8}$ G. Herzer, IEEE Trans. Magn. 26, 1397 (1990).

${ }^{9}$ R. Hasegawa, J. Optoelectron. Adv. Mater. 6(2), 503 (2004).

${ }^{10}$ M. E. McHenry et al., Prog. Mater. Sci. 44, 291 (1999).

${ }^{11}$ H. Q. Guo et al., J. Appl. Phys. 89, 514 (2001).

${ }^{12}$ J. Arcas et al., Nanostruct. Mater. 7(8), 823 (1996).

${ }^{13}$ H. Chiriac et al., J. Appl. Phys. 83, 6584 (1998).

${ }^{14}$ C. Dudek et al., J. Non-Cryst. Solids 353, 925 (2007).

${ }^{15}$ G. Herzer, J. Magn. Magn. Mater. 294, 99 (2005).

${ }^{16}$ J. M. Blanco et al., J. Appl. Phys. 87(9), 4813 (2000).

${ }^{17}$ H. Chiriac et al., J. Magn. Magn. Mater. 254-255, 469 (2003).

${ }^{18}$ H. Chiriac et al., Phys. Rev. B 52, 10104 (1995).

${ }^{19}$ A. S. Antonov et al., J. Phys. D: Appl. Phys. 33, 1161 (2000).

${ }^{20}$ M. Tejedor et al., J. Magn. Magn. Mater. 185, 61 (1998).

${ }^{21}$ Yu. Kabanov et al., Appl. Phys. Lett. 87, 142507 (2005).

${ }^{22}$ B. Hernando et al., Phys. Met. Metallogr. 102, S13 (2006).

${ }^{23}$ Y.-H. Zhang et al., J. Alloys Compd. 491, 589 (2010).

${ }^{24}$ L. Onsager, Phys. Rev. 37, 405 (1931).
} 